\section{MEDICOLEGAL LIABILITY OF PATIENTS DRIVING UNDER THE INFLUENCE (DUI)}

To the editor:

In healthcare settings, point-of-care testing (POCT) for drugs is routinely performed to monitor patients' compliance with medications as prescribed to them and to detect their self-administration of any untoward drugs which may be potentially dangerous in combination with prescribed medications. Essentially, POCT guides the healthcare providers regarding the changes (if any) needed in their patients' management plans. However, have healthcare providers ever wondered about the medicolegal liability as related to POCT especially when the detected drugs in patients' systems may deem them too impaired or too intoxicated to drive back to home safely after their healthcare encounters? Are healthcare providers aware about what their states' laws state and how their states' law enforcement officers test to rule out whether the drivers are "Operating While Visibly Impaired (OWVI)"1 or "Operating While Intoxicated (OWI)" "which are two types of charges per State of Michigan when defining driving under the influence (DUI) or driving while impaired/intoxicated (DWI)? Additionally, the State of Michigan has two more types of charges against "Operating With Any Presence of a Schedule 1 Drug or Cocaine (OWPD)"1 and "Under Age 21 Operating With Any Bodily Alcohol Content (Zero Tolerance)."1

Being practitioners in State of Michigan, the concerning scenarios can be as following in physicians' offices or hospitals' emergency departments or those healthcare encounters wherein patients are driving back to home soon thereafter:

In the healthcare settings, can healthcare providers perform "Standardized Field Sobriety Tests (SFST)"2 as performed by law enforcement officers namely "Horizontal Gaze Nystagmus,"2 "Walk and Turn,"2 and "One-Leg Stand" 2 to confirm whether visibly impaired patients are truly impaired to drive back to home (OWVI)?

Regarding persons covered under the Americans with Disabilities Act of 1990 amended in 2008, ${ }^{3}$ can physical conditions and symptoms like pain preclude patients from appropriately performing SFST in healthcare settings even though they may be physically able to drive back to home safely in spite of their physical conditions and symptoms like pain? Will POCT for drugs despite preclusion of SFST be appropriate for such persons to rule out drug-related impairment/intoxication?

After SFST in healthcare settings confirm the concerns for OWVI if patients driving back to home, can healthcare providers perform POCT for drugs to confirm intoxication levels to prevent OWI?

In the healthcare settings, can the positive results of fast-turnover qualitative POCT for drugs and definitive results of slow-turnover quantitative POCT for drugs expect that the healthcare providers should strongly deter such patients from OWI?

As similar to Michigan Liquor Control Code of 1998 (Act 58 of 1998; popularly known as "Dram Shop Act") Section 436.1801 holding entities and persons selling or giving liquor to visibly intoxicated persons potentially liable for damages in the event of untoward incidents caused by those visibly intoxicated persons, are healthcare providers ethically and/or medico-legally liable when their patients drive back to home after their healthcare providers may have overlooked to prohibit OWVI/OWI in such patients who had tested positive during SFST and/or POCT for drugs performed in the healthcare settings for patient-and-road safety reasons as stated above or for patients' medical management plans as stated in the very beginning?

When deciding to prohibit their patients from driving back to home, should the healthcare providers follow the same legal limits as what State of Michigan laws state: (a) bodily alcohol content (BAC) $\geq 0.08$ if age $\geq 21$ years; (b) $\mathrm{BAC} \geq 0.02$ if age $<21$ years; and (c) presence of any Schedule 1 drug or cocaine in the body? ${ }^{1}$ 
For the sake of patient-and-road safety, should the healthcare providers inform and involve law enforcement officers when the patients themselves decide to overlook the prohibition by their healthcare providers regarding OWVI/OWI/OWPD/Zero-Tolerance?

Forgoing reliance on healthcare providers' unpredictable vigilance to visibly appreciate patients' impairment to safely drive back to home, will it be an exaggeratedly cautious move by healthcare providers to ask every patient to appropriately perform SFST if he/she is planning to drive back to home after his/her healthcare encounter?

Until there is a defined quantifiable limit of allowable marihuana levels inside the body as similar to the set limits for seven abused drugs' levels and nine licensed medications' levels under the Road Traffic Act 1988 amended in 2013 and enforced by Department of Transport in the United Kingdom since $2015,{ }^{5}$ what are the responsibilities of healthcare providers when discovering POCT being positive for quantifiable marihuana considering that, although the Michigan Regulation and Taxation of Marihuana Act (Initiated Law 1 of 2018) Section $333.27954^{6}$ does not authorize operating and driving under the influence of recreational marihuana and Michigan Medical Marihuana Act (Initiated Law 1 of 2008) Section $333.26424 \mathrm{~b}^{7}$ does not allow transport of unsealed-unlabeled-unpacked medical marihuana in a motor vehicle, pharmaceutical-grade cannabis (and marihuana) is a Schedule 2 drug in State of Michigan under Public Health Code (Act 368 of 1978) Section 333.7212 (subsection 2$)^{8}$ with exceptions as defined in the Act's Division 3681978-8-81A??

Summarily, with legalization of medical and recreational marihuana use in State of Michigan just like many other states which all are at various stages in legalizing marihuana use within their borders, the healthcare providers and healthcare facilities should consider reviewing their states' laws as well as their institutional policies to decide appropriate plans for ethically and medico-legally managing their patients when there are patient-and-road safety concerns for OWVI/OWI/OWPD/Zero-Tolerance as unraveled by SFST and/or POCT for drugs.

Deepak Gupta, MD

Clinical Assistant Professor

Department of Anesthesiology

Wayne State University

Detroit, Michigan

Shushovan Chakrabortty, MD, PhD

Clinical Assistant Professor

Department of Anesthesiology

Wayne State University

Detroit, Michigan

\section{REFERENCES}

1. State of Michigan: Secretary of State: Department of State. Substance Abuse and Driving. Available at https://www.michigan. gov/sos/0,4670, 7-127-1627_8665-24488-,o0.html Accessed February 22, 2019.

2. Thomson Reuters: FindLaw. Field Sobriety Tests. Available at bttps://dui.findlaw.com/dui-arrests/field-sobriety-tests.html Accessed February 22, 2019.

3. US Equal Employment Opportunity Commission. ADA Amendments Act of 2008. Available at https://www.eeoc.gov/ laws/statutes/adaaa.cfm Accessed February 22, 2019.

4. Michigan Legislature. Chapter 436. Act 58 of 1998. Division 58-1998-8. Section 436.1801. Available at http://www.legislature. mi.gov/(S(uzqqhfa35wmtdpnrim3mbvdo))/mileg.aspx:page $=$ Get ObjectEobjectname $=m c l-436-1801$ Accessed February 22, 2019.

5. Department for Transport. Guidance for healthcare professionals on drug driving. Available at https://assets.publishing.service. gov.uk/government/uploads/system/uploads/attachment_data/ file/325275/healthcare-profs-drug-driving.pdf Accessed February 22, 2019.

6. Michigan Legislature. Chapter 333. Initiated Law 1 of 2018. Section 333.27954. Available at https://www.legislature.mi.gov/ $(S(3 a i l t v b r 2 t d 25 n x$ sasOixjjq))/mileg.aspx?page $=$ getObjectEobject Name $=$ mcl-333-27954 Accessed February 22, 2019.

7. Michigan Legislature. Chapter 333. Initiated Law 1 of 2008. Section 333.26424b. Available at http://www.legislature.mi.gov/ (S(fu2vObeo13hxmnyh2yssxpg2))/mileg.aspx:page=getObject $\varepsilon$ objectName $=m c l-333-26424 b$ Accessed February 22, 2019.

8. Michigan Legislature. Chapter 333. Act 368 of 1978. Division 368-1978-7-72. Section 333.7212. Available at http://www.legisla ture.mi.gov/(S(t2dcui3kpmai5haigwsceyOz))/mileg.aspx:page=get objectEobjectname=mcl-333-7212 Accessed February 22, 2019.

9. Michigan Legislature. Chapter 333. Act 368 of 1978. Division 368-1978-8-81A. Available at http://www.legislature.mi.gov/ (S(gm2o3nstnlksl1iqjwsjdf4b))/mileg.aspx:page=getObjectEobje ctName=mcl-368-1978-8-81A Accessed February 22, 2019. 